\title{
A COST OPTIMISED PROCESS MEAN SET POINT FOR TWO SIDED SPECIFICATIONS
}

\author{
W. van Wijck \& M. von Benecke \\ Department of Industrial Engineering \\ University of Stellenbosch
}

\begin{abstract}
This paper describes the derivation of cost minimising expressions to optimally set the process mean of a manufacturing process restricted by a double-sided specification. Two scenarios are considered. For the first scenario, multiple reworking iterations are possible, while in the second, only one rework opportunity is allowed. A numerical example is also presented. Results were obtained by numerical solution and are presented in graphical format.
\end{abstract}

\section{OPSOMMING}

Hierdie artikel beskryf die afleiding van koste-minimerende uitdrukkings wat die proses-gemiddelde van 'n vervaardigingsproses wat deur ' $n$ twee-kantige spesifikasie beperk word, optimaal daar stel. Twee gevalle word oorweeg. In die eerste geval is verskeie herwerk-iterasies moontlik, terwyl die tweede geval slegs een herwerk-geleentheid aanvaar. 'n Numeriese voorbeeld word ook bespreek. Resultate is deur numeriese analise verkry en word grafies voorgestel. 


\section{INTRODUCTION}

Many manufacturing processes, when under statistical control, exhibit fixed probabilities connected to the incidence of both scrap and rework. In a machining process, scrap is usually associated with too much material having been removed, and rework is associated with not enough machining having been done. The presence of finishing defects is also related to rework.

Definite costs are associated with the occurrence of both scrap and rework and these costs are normally not the same. For a given process dispersion and technical specification, it remains within the control of the operations manager to set the process mean to such a value that the total cost of scrap and rework will be a minimum. The need and importance of this are widely appreciated, e.g. Grant [5].

The above problem is addressed in this paper and two production scenarios are considered.

\section{LIST OF SYMBOLS USED}

$\sigma \quad$ Standard deviation of process output for a process assumed to be under statistical control Location (constant mean) of process which is assumed to be under statistical control

$\phi(x) \quad$ Cumulative distribution function (c.d.f.) of a standard normal random variable $x$

$C \quad$ Ratio of material cost plus original manufacturing cost to that of rework

$C_{s} \quad$ Sum of material and production cost per unit up to the current manufacturing operation

$C_{p} \quad$ Index that measures potential or inherent capability of the production process assuming a stable process

$C_{r} \quad$ Rework cost per unit for the current manufacturing operation

$f_{x}(x ; \mu) \quad$ Probability density function (p.d.f.) of process output with mean set at a value of $\mu$

$F_{x}(x ; \mu) \quad$ Cumulative distribution function (c.d.f.) of process output with mean set at a value of $\mu$

$I \quad$ Size of a production lot that would ensure the production of $\mathrm{N}$ good items

LSL Lower limit of design specification

$N \quad$ Number of good items out of a production lot of size $I$

N.S. Nominal specification i.e. midpoint of design specification

$P_{s} \quad$ Probability of scrap at a given machine setting

$P_{r} \quad$ Probability of rework at a given machine setting

TPC Total production cost to make $N$ good items

TPCPU Total production cost per good item that is manufactured

TRPCPU Total relevant production cost per good item that is manufactured

USL Upper limit of design specification

w Specification width (in relative terms): expressed as a number of standard deviations of process output

$W \quad$ Specification width (in absolute terms)

$x \quad$ Value of a quality characteristic of a manufactured unit 
$X \quad$ Random variable that describes the value of a quality characteristic of a manufactured item

$y \quad$ Offset of process mean relative to nominal specification (in relative terms): expressed as number of standard deviations of process output

$Y \quad$ Offset of process mean relative to nominal specification (in absolute terms): i.e. $\mu-N . S$.

\section{DESCRIPTION OF THE TWO PRODUCTION SCENARIOS CONSIDERED}

The probabilities for the occurrence of scrap and rework in a manufacturing process that is fairly well under control, would remain largely constant over time. For such a manufacturing process, let the probability of a part being scrapped at a particular stage of manufacture be $P_{s}$, and let the probability of it requiring rework at that stage, be $P_{r}$. Also, set the sum of the material cost and the cost of production up to and including that point, at $C_{s}$, and that of rework at that specific stage in the manufacturing process, to an average of $C_{r}$.

A reworked item is essentially recycled in the manufacturing process. In the first instance considered (scenario A), multiple reworking iterations are allowed. In the interest of simplicity, it is assumed that the number of times an item has been reworked previously, has no effect on the probability of it requiring reworking at the end of the next cycle or production stage. In the second instance (scenario B), only one rework opportunity is allowed. The transition-state diagrams of the two scenarios are illustrated in figures (1a) and (1b) respectively.

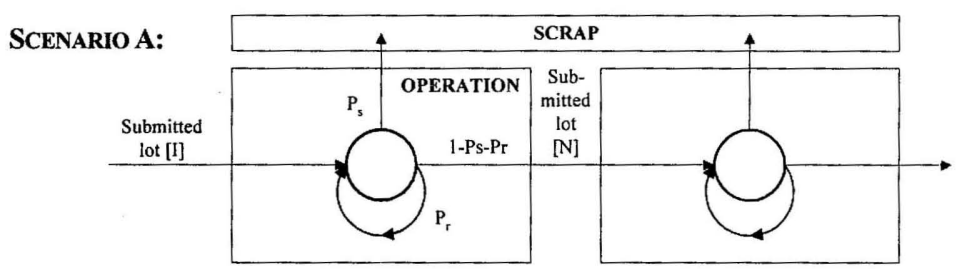

Figure 1a

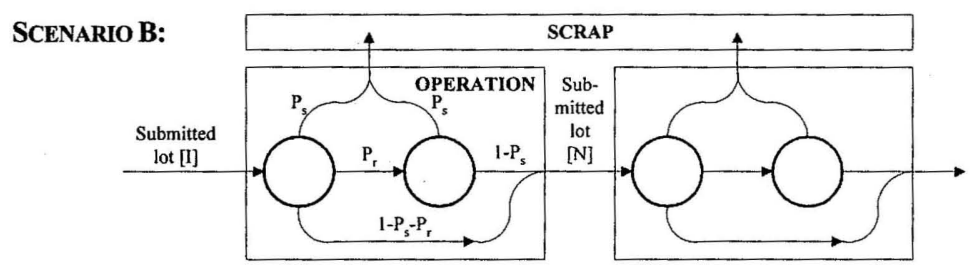

Figure $1 b$

When considering scenario A (refer to figure 1a), the number of good items $N$ being produced in a run of $I$ units, is:

$$
\begin{aligned}
N & =I \cdot\left(1-P_{r}-P_{s}\right)+I \cdot P_{r} \cdot\left(1-P_{r}-P_{s}\right)+I \cdot P_{r}^{2} \cdot\left(1-P_{r}-P_{s}\right)+\ldots \\
& =I .\left(1-P_{r}-P_{s}\right) \cdot\left(1+P_{r}+P_{r}^{2}+P_{r}^{3}+\ldots\right)
\end{aligned}
$$




$$
=I .\left(\frac{1-P_{r}-P_{S}}{1-P_{r}}\right) \quad \text { for } P_{r}<1
$$

The population $I$ of units required to be manufactured in order to produce $N$ good units is by rearrangement of the above terms:

A: $\quad I=N \cdot\left(\frac{1-P_{r}}{1-P_{r}-P_{s}}\right)$

On the other hand, when considering scenario $\mathrm{B}$, the number of good items $N$ being produced in a run of $I$ units, is:

$$
\begin{aligned}
N & =I \cdot\left(1-P_{r}-P_{S}\right)+I \cdot P_{r} \cdot\left(1-P_{s}\right) \\
& =I .\left(1-P_{s}-P_{r} P_{s}\right) \quad \text { for } P_{r}<1
\end{aligned}
$$

The population $I$ of units required to be manufactured in order to produce $N$ good units is by rearrangement of the above terms:

B: $\quad I=N\left(\frac{1}{1-P_{s}-P_{r} P_{s}}\right)$

\section{TOTAL PRODUCTION COSTS FOR THE TWO SCENARIOS}

The expressions derived in the previous section can be used to calculate the total production $\operatorname{cost}, T P C$, to produce $N$ good units for scenarios A and B respectively.

A: $\quad T P C=I \cdot C_{s}+I \cdot\left(\frac{P_{r}}{1-P_{r}}\right) \cdot C_{r}$

where $I \cdot\left(\frac{P_{r}}{1-P_{r}}\right)=$ the total number of rework cycles necessary to produce $N$ good items.

B: $\quad T P C=I . C_{S}+I \cdot P_{r} \cdot C_{r}$

In terms of equations (1a) and (1b), the above expressions can be written as:

A: $\quad T P C=N\left(\frac{C_{s}-P_{r} \cdot C_{s}+P_{r} \cdot C_{r}}{1-P_{r}-P_{s}}\right)$

B: $\quad T P C=N \cdot\left(\frac{C_{s}+P_{r} \cdot C_{r}}{\left.1-P_{s}-P_{r} \cdot P_{s}\right)}\right)$

By dividing the former equations by $N$, the production cost per good unit is obtained as:

A: $\quad T P C P U=\frac{C_{s}-P_{r} \cdot C_{s}+P_{r} \cdot C_{r}}{1-P_{r}-P_{s}}$

B: $\quad T P C P U=\frac{C_{s}+P_{r} \cdot C_{r}}{1-P_{s}-P_{r} \cdot P_{s}}$

Hence, the problem is to arrive at a set point for the process mean relative to the nominal specification that would minimise the TPCPU. Before proceeding to minimise the total unit cost given by equations 
(2a) and (2b), it is useful to simplify these equations by dividing the TPCPU by $C_{r}$ (division or multiplication by a constant will not in any way affect the value of the dependent variable for which $T P C P U$ will be a minimum) and setting the cost ratio to:

$$
\left(\frac{C_{s}}{C_{r}}\right)=C
$$

This simplification leads to the following two expressions that represent relative measures of the total production cost per unit.

A: $\quad T R P C P U=\frac{C-P_{r} \cdot C+P_{r}}{1-P_{r}-P_{s}}$

B: $\quad T R P C P U=\frac{C+P_{r}}{1-P_{s}-P_{r} \cdot P_{s}}$

\section{GENERAL CASE: THE PROCESS OUTPUT HAS A GENERAL $p$.d.f.}

Figure (2) depicts the case where the output of a manufacturing process follows any general probability density function $f_{x}(x ; \mu)$ with process mean $\mu$. Acceptable production units are considered those units that would fall within the upper and lower specification limits denoted by USL and LSL respectively.

With $P_{s}$ and $P_{r}$ arbitrarily chosen as illustrated in figure (2), with scrap being associated with low values of the quality characteristic and rework with high values thereof, it is evident that:

$$
P_{S}=F_{x}(L S L ; \mu) \text { and } P_{r}=1-F_{x}(U S L ; \mu)
$$

The position of the process mean relative to the nominal specification (i.e. the midpoint of the design specification) is given by:

$$
\mu=N . S+Y
$$

with $F_{x}(x ; \mu)$ representing the cumulative distribution function (c.d.f.) of the process output $x$. The offset $Y=\mu-N . S$ will therefore be negative when the process mean is set below the nominal specification and positive otherwise.

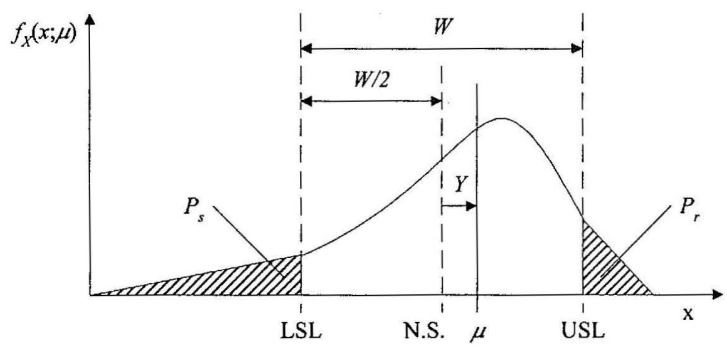

Figure 2

Also, the position of the USL and the $L S L$ relative to the process mean may be stated as: 


$$
L S L=\mu-Y-\frac{W}{2} \text { and } U S L=\mu-Y+\frac{W}{2}
$$

where $\mu=$ process mean, $W=$ specification width and $Y=$ difference between the process mean and the nominal specification.

By substituting the relationships of equation (4) into equations (3a) and (3b), the following equations relating the TRPCPU to the process-offset $Y$, are obtained for both scenarios from which the optimum process-offset can be calculated:

$$
\begin{aligned}
& \text { A: } \quad \operatorname{TRPCPU}=\frac{C \cdot F_{x}\left\{\mu-Y+\frac{W}{2} ; \mu\right\}+1-F_{x}\left\{\mu-Y+\frac{W}{2} ; \mu\right\}}{F_{x}\left\{\mu-Y+\frac{W}{2} ; \mu\right\}-F_{x}\left\{\mu-Y-\frac{W}{2} ; \mu\right\}} \\
& \text { B: } \quad T R P C P U=\frac{C+1-F_{x}\left\{\mu-Y+\frac{W}{2} ; \mu\right\}}{1-2 \cdot F_{x}\left\{\mu-Y-\frac{W}{2} ; \mu\right\}+F_{x}\left\{\mu-Y-\frac{W}{2} ; \mu\right\} \cdot F_{x}\left\{\mu-Y+\frac{W}{2} ; \mu\right\}}
\end{aligned}
$$

Setting the derivatives of equations (7a) and (7b) with respect to $Y$ equal to zero and carrying out some algebraic manipulation and simplification, the following expressions result for the calculation of the optimum offset for scenarios A and B:

A:

$$
\frac{f_{x}\left\{\mu-Y+\frac{W}{2} ; \mu\right\}}{f_{x}\left\{\mu-Y-\frac{W}{2} ; \mu\right\}}=\frac{(C-1) \cdot F_{x}\left\{\mu-Y+\frac{W}{2} ; \mu\right\}+1}{(C-1) \cdot F_{x}\left\{\mu-Y-\frac{W}{2} ; \mu\right\}+1}
$$

$\mathrm{B}: \frac{f_{x}\left\{\mu-Y+\frac{W}{2} ; \mu\right\}}{f_{x}\left\{\mu-Y-\frac{W}{2} ; \mu\right\}}=\frac{\left[2-F_{x}\left\{\mu-Y+\frac{W}{2} ; \mu\right\}\right]\left[C+1-F_{x}\left\{\mu-Y+\frac{W}{2} ; \mu\right\}\right]}{(C-1) \cdot F_{x}\left\{\mu-Y-\frac{W}{2} ; \mu\right\}+1}$

\section{SPECIAL CASE: PROCESS OUTPUT HAS A NORMAL $p . d . f$.}

In order to simplify and standardise the relationships that follow, it is useful to express the mean-offset, $Y$, and specification width, $W$, as multiples of the process dispersion, $\sigma$, by defining:

$$
\begin{aligned}
& y=\frac{Y}{\sigma}=\text { offset in number of process standard deviations } \\
& w=\frac{W}{\sigma}=\text { specification width in number of process standard deviations }
\end{aligned}
$$

Let $\phi$ denotes the $c . d . f$. of the standard normal distribution. Using equations (7a) and (7b) and the above expressions, the TRPCPU for the two scenarios become: 
A: TRCPU $=\frac{C \cdot \phi\left\{-y+\frac{w}{2}\right\}+1-\phi\left\{-y+\frac{w}{2}\right\}}{\phi\left\{-y+\frac{w}{2}\right\}-\phi\left\{-y-\frac{w}{2}\right\}}$

B: $\quad T R C P U=\frac{C+1-\phi\left\{-y+\frac{w}{2}\right\}}{1-2 . \phi\left\{-y-\frac{w}{2}\right\}+\phi\left\{-y-\frac{w}{2}\right\} \cdot \phi\left\{-y+\frac{w}{2}\right\}}$

The special instance of the normal distribution leads to the following four expressions that apply to both scenarios:

$$
\begin{aligned}
& f_{x}\left\{\mu-Y+\frac{W}{2} ; \mu\right\}=\frac{1}{\sqrt{2 \pi} \sigma} \cdot e^{-\frac{1}{2} \cdot\left\{\left(\frac{-Y}{\sigma}\right)+\frac{1}{2} \cdot\left(\frac{W}{\sigma}\right)\right\}^{2}}=\frac{1}{\sqrt{2 \pi} \sigma} \cdot e^{-\frac{1}{2} \cdot\left\{-y+\frac{1}{2} w\right\}^{2}} \\
& f_{x}\left\{\mu-Y-\frac{W}{2} ; \mu\right\}=\frac{1}{\sqrt{2 \pi} \sigma} \cdot e^{-\frac{1}{2} \cdot\left\{\left(\frac{-Y}{\sigma}\right)-\frac{1}{2} \cdot\left(\frac{W}{\sigma}\right)\right\}^{2}}=\frac{1}{\sqrt{2 \pi} \sigma} \cdot e^{-\frac{1}{2} \cdot\left\{-y-\frac{1}{2} w\right\}^{2}} \\
& F_{x}\left\{\mu-Y+\frac{W}{2} ; \mu\right\}=\phi\left\{\left(\frac{-Y}{\sigma}\right)+\frac{1}{2} \cdot\left(\frac{W}{\sigma}\right)\right\}=\phi\left\{-y+\frac{1}{2} w\right\} \\
& F_{x}\left\{\mu-Y-\frac{W}{2} ; \mu\right\}=\phi\left\{\left(\frac{-Y}{\sigma}\right)-\frac{1}{2} \cdot\left(\frac{W}{\sigma}\right)\right\}=\phi\left\{-y-\frac{1}{2} w\right\}
\end{aligned}
$$

Finally, substituting equations (10) into equations ( $8 \mathrm{a})$ and $(8 \mathrm{~b})$, the following expressions are obtained from which the optimum process location, $y$, can be determined iteratively for the two scenarios:

$$
\begin{aligned}
& \text { A: } \quad y=\frac{1}{w} \cdot \ln \left[\frac{(C-1) \cdot \phi\left\{-y+\frac{w}{2}\right\}+1}{(C-1) \cdot \phi\left\{-y-\frac{w}{2}\right\}+1}\right] \\
& \text { B: } \quad y=\frac{1}{w} \cdot \ln \left[\frac{\left[2-\phi\left\{-y+\frac{w}{2}\right\}\right]\left[C+1-\phi\left\{-y+\frac{w}{2}\right\}\right]}{(C-1) \cdot \phi\left\{-y-\frac{w}{2}\right\}+1}\right]
\end{aligned}
$$

Figures (3a) and (3b) are graphs of the offset, $y$, vs. the specification width, $w$, for the cost ratio, $C$, equal to the values $5,10,20,50$ and 100 respectively. The values for the different cost ratios indicate that the cost of scrapping the part is equal to five times the rework cost, ten times the rework cost, twenty times the rework cost, and finally one hundred times the rework cost. The first instance applies early in the manufacturing process and the latter towards the end after numerous stages.

The $C_{p}$ index that measures potential or inherent capability of the production process (assuming a stable process) is also shown for both scenarios in figures (3a) and (3b). This index is defined as:

$$
C_{p}=\frac{U S L-L S L}{6 \sigma}=\frac{w}{6}
$$


From figures (3a) and (3b) it is evident that the narrower the specification width and the greater the cost ratio $C=\frac{C_{s}}{C_{r}}$ (i.e. the lower the relative cost of rework), the greater the offset is required to be in absolute and especially in relative terms, i.e. in comparison with the specification width. This is the situation after numerous production stages, when the total value added to the part becomes high. In other words, $C_{s}$ is a cumulative cost that adds up as the item progresses through the various manufacturing stages or operations. On the other hand, $C_{r}$, is the average rework cost per rework operation. Therefore, the cost ratio, $C=\frac{C_{s}}{C_{r}}$, will increase as the item proceeds through its various manufacturing operations.

Scenario A

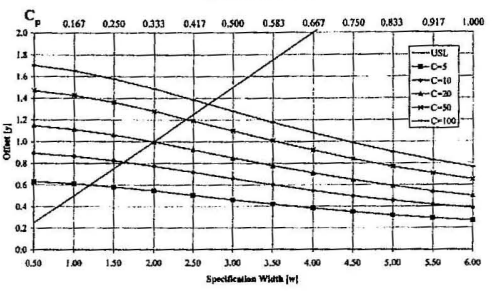

Figure 3a

Scenario A

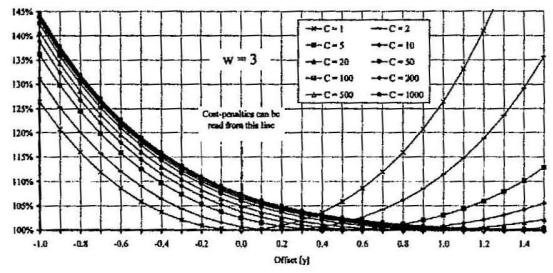

Figure 4a

Scenario A

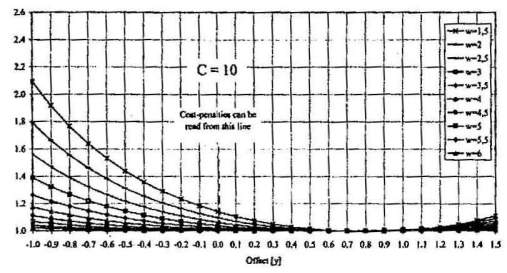

Figure 5a

\section{Scenario B}

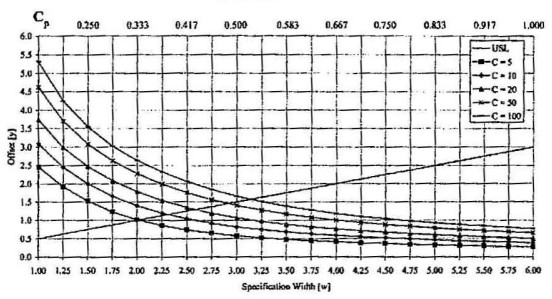

Figure 3b

Scenario B

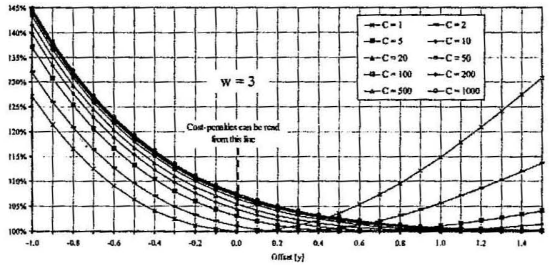

Figure 4b

Scenario B

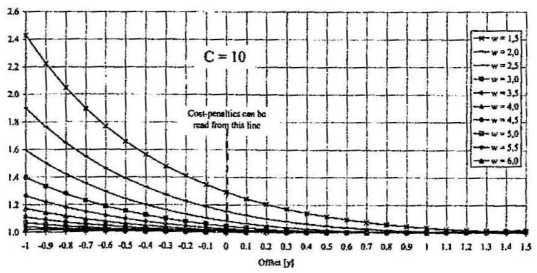

Figure 5b 
Figures (4a) and (4b) depict graphs of the total relevant production costs per unit from equations (9a) and $(9 \mathrm{~b})$, vs. the process mean offset, $y$. These graphs have been normalised by the minimum TRPCPU attainable at the optimal offset. The $y$-axis thus shows the actual cost per unit as a percentage of the minimum possible cost. Figures (5a) and (5b) contain graphs showing how the optimum process offset varies with the specification width (process capability) for a fixed cost ratio $\mathrm{C}$ of 10 . Figures (5a) and $(5 b)$ should be viewed in conjunction with figures (4a) and (4b).

\section{A SPECIAL SIMPLIFIED CASE}

The theory above may be simplified for both scenarios when applied to a process that normally generates small percentages of scrap and rework. To illustrate, equations (3a) and (3b) may be rewritten as follows:
A: $\quad T R P C P U=\left(C-P_{r} \cdot C+P_{r}\right) \cdot\left[1+\left(P_{s}+P_{r}\right)+\left(P_{s}+P_{r}\right)^{2}+\ldots\right]$
(equation 3a rewritten)
B: $\quad T R P C P U=\left(C-P_{r} \cdot C+P_{r}\right) \cdot\left[1+P_{s}\left(1-P_{r}\right)+P_{s}^{2}\left(1-P_{r}\right)^{2}+\ldots\right]$
(equation $3 \mathrm{~b}$ rewritten)

When $P_{s}$ and $P_{r}$ are small, the effect of second and higher order product terms in the above two equations can be ignored. TRPCPU for both scenarios may then be approximated by the following equation:

$$
T R P C P U=C \cdot\left(1+P_{s}\right)+P_{r}
$$

Using the previous reasoning the following simplified expression, to solve for the optimal process mean offset, is derived:

$$
\frac{f\left\{\mu-Y+\frac{W}{2} ; \mu\right\}}{f\left\{\mu-Y-\frac{W}{2} ; \mu\right\}}=C
$$

For the special case of the normal distribution the optimal process mean offset is given by:

$$
y=\frac{\ln (C)}{w}
$$

Equation (13) allows $y$ (and $Y$ ) to be calculated explicitly, but represents an approximation valid only for small probabilities for work being out of specification. The practical value of this simplification is questionable and probably limited, because for small $P_{r}$ and $P_{s}$ (a process with good capability), there is little need to adjust the process mean for optimality.

\section{NUMERICAL EXAMPLE}

\section{Problem statement:}

A steel shaft that forms part of the armature assembly of an electrical motor requires various successive machining operations before attaining its final form and dimensions. During one of the operations where the shaft is machined on a centre lathe, the outside diameter is machined according to the following tolerance specification: $10.00 \mathrm{~mm} \pm 0.05 \mathrm{~mm}$ (with the process output being normally distributed).

Historical data for this operation has indicated a poor capability index $C_{p}$ of only 0.70 , partly due to the age and physical condition of the lathe. Shafts with diameters below $9.95 \mathrm{~mm}$ must be scrapped, while those with diameters above $10.05 \mathrm{~mm}$ must be reworked to bring them within the specified tolerance range. 
The raw material from which the shaft is made, costs R 30.00 , and the labour and overhead costs, up to and including this particular operation, amounts to $\mathrm{R} 60.00$. The average cost to rework a shaft on the centre lathe is estimated at $\mathrm{R} 10.00$.

\section{Solution:}

From the problem statement, the value of the cost component $C_{s}=\mathrm{R} 30+\mathrm{R} 60=\mathrm{R} 90$.

The cost ratio $C=\frac{R 90}{R 10}=9$

The process dispersion, $\sigma$, can be calculated as follows:

$$
C_{p}=0.70=\frac{U S L-L S L}{6 \sigma}=\frac{10.05-9.95}{6 \sigma}=\frac{0.1}{6 \sigma} . \text { Therefore } \sigma=0.02381
$$

The specification width (expressed as a number of process standard deviations) $=w=\frac{10.05-9.95}{0.02381}=4.2$

If the process is adjusted to run on the nominal specification (zero-offset), then by referring to figure (2), $P_{s}$ and $P_{r}$ can be calculated as:

$$
P_{r}=P_{s}=\phi\left\{\frac{9.95-10.00}{0.02381}\right\}=\phi\{-2.1\}=0.01786
$$

\section{Scenario A:}

When considering scenario A, the total production cost per unit, for an acceptable shaft (the outside diameter falling within the specified tolerance range) when the process is centred on the nominal specification of $10.00 \mathrm{~mm}$, can be calculated using equation (2a) and the obtained values for $P_{r}$ and $P_{s}$ :

$$
\begin{aligned}
T P C P U & =\frac{(1-0.01786) \cdot R 90+(0.01786) \cdot R 10}{1-0.01786-0.01786} \\
& =R 91.85
\end{aligned}
$$

The optimum offset (in relative terms, i.e. $y$ ) was obtained from equation (11a) using Microsoft Excel's SOLVER as:

$$
y=0.50254
$$

Therefore, the process offset in absolute terms $=Y=y \cdot \sigma=(0.50254) \cdot(0.02381)=0.01197 \mathrm{~mm}$

Assuming that it is possible to accurately adjust and set the location of this process, $P_{s}$ and $P_{r}$ can be recalculated for the optimum offset above, as follows:

$$
P_{s}=\phi\left\{\frac{9.95-0.01197}{0.02381}\right\}=0.00461 \text { and } P_{r}=\phi\left\{\frac{10.05-0.01197}{0.02381}\right\}=0.05524
$$

For this optimum process mean setting, the new TPCPU can again be calculated using equation (2a) as:

$$
\begin{aligned}
T P C P U & =\frac{(1-0.05524) \cdot R 90+(0.05524) \cdot R 10}{1-0.05524-0.00461} \\
& =R 91.03
\end{aligned}
$$

For this specific example a saving of R0.82 (0,89\%) per shaft is possible. 


\section{Scenario B:}

When considering scenario $\mathrm{B}$, where only one rework opportunity is allowed, the total production cost per unit for an acceptable shaft (the outside diameter falling within the specified tolerance range) when the process is centred on the nominal specification of $10.00 \mathrm{~mm}$, can be calculated using equation ( $2 \mathrm{~b}$ ) (note that as before, $P_{s}=P_{r}=0.01786$ ):

$$
T P C P U=\frac{R 90+(0.01786) \cdot R 10}{1-(0.01786) \cdot(1+0.01786)}=R 91.85
$$

It is interesting to note that for this specific cost structure and process capability, the two scenarios produce the same total production cost per good unit when the process is set to run on the nominal specification. For scenario B, the optimum process offset (in relative terms, i.e. $y$ ) was obtained from equation (11b), again using Microsoft Excel's SOLVER, as:

$$
y=0.53017
$$

Therefore, the process offset in absolute terms $=Y=y . \sigma=(0.53017) .(0.02381)=0.01262 \mathrm{~mm}$

Again assuming it is possible to accurately locate this process, $P_{s}$ and $P_{r}$ for the new optimum process location, can be recalculated as follows:

$$
P_{s}=\phi\left\{\frac{9.95-10.01262}{0.02381}\right\}=0.00407 \text { and } P_{r}=\phi\left\{\frac{10.05-10.01262}{0.02381}\right\}=0.06009
$$

The TPCPU with this setting is as follows:

$$
T P C P U=\frac{R 90+(0.06009) \cdot R 10}{1-(0.00407) \cdot(1+0.06009)}=R 90.99
$$

The expected saving in this case is fractionally more than for scenario A and amounts to R $0.86(0.94 \%)$.

\section{CONCLUSION}

Although only modest savings were obtained in the previous example, much larger savings are possible with greater cost ratios ( $C$ equal to 20 or higher) and less capable processes. This is evident from figures (4a), (4b), (5a) and (5b). The modern manufacturing environment is marked by fierce competition in the drive towards global competitiveness and world class performance, as suggested by Christopher and Dornier [3][2]. The reduction in scrap and rework cost that is attainable from the proposed method to determine and set the optimum location of a process, should be measured and viewed against the uncompromising efforts by world leaders to consistently strive for zero defects, e.g. Goetsch [4] and process perfection, e.g. Christopher [2]. This obsession to continuously improve is particularly evident from MOTOROLA's increasingly popular 6-sigma concept in which the concept of process capability is almost redefined evident from Goetsch and Chase [4][1]. Yes, the obvious starting point for implementing this proposed strategy is with processes having poor or marginal capability, but in accordance with modern day trends, all processes bounded by a double-sided specification should ultimately be viewed as potential candidates that could benefit from this strategy.

The optimal offset for the process mean is larger for scenario B than for scenario A, although the potential saving is roughly the same.

It should be noted that in the mathematical formulation of the problem, scrap was assumed to be items with smaller values of the quality characteristic than rework. Under this assumption, the optimal process setpoint will always have positive offsets (positive $y$-values). However, if scrap is generated at high 
values of the quality characteristic and rework at low values, then the theory can still be applied, but the optimal offset value must be given a negative sign.

To conclude, it is interesting to observe that the form of the cost curves depicted in figures (4a), (4b), (5a) and (5b), seem to confirm the relevance and shape of Taguchi's parabolic Loss Function.

\section{REFERENCES}

[1] Chase, R. B. and Aquilano, N. J. (1992), Production and Operations Management, Sixth Edition, Richard D. Irwin, Chicago, pp. 245.

[2] Christopher, M. (1997), Marketing Logistics, Butterworth-Heinemann, Oxford, pp. 1-24, 42-44, 72$73,93-117,139-147$.

[3] Dornier, P., Ernst, R., Fender, M. and Kouvelis, P. (1998), Global Operations and Logistics - Text and Cases, John Wiley \& Sons, Inc., New York, pp. 8-9, 40-41, 75-113, 306-356.

[4] Goetsch, D. L. and Davis, S. B. (1997), Introduction to Total Quality - Quality Management for Production, Processing, and Services, Second Edition, Prentice Hall, New Jersey, pp. 158, 186.

[5] Grant, E. L. and Leavenworth, R. S. (1980), Statistical Quality Control, Fifth Edition, McGraw-Hill International Book Company, Tokyo, pp. 133. 